\section{OPEN ACCESS}

Edited by:

Vincent Kam Wai Wong,

Macau University of Science

and Technology, China

Reviewed by:

Lei Cheng,

Kiang Wu Hospital, China

Yun Zhang

Macau University of Science

and Technology, China

*Correspondence:

Chaoying Ma

mcy195888@126.com

Xiaojuan $\mathrm{He}$

hxj19@126.com

tThese authors have contributed equally to this work.

Specialty section: This article was submitted to

Ethnopharmacology,

a section of the journal

Frontiers in Pharmacology

Received: 20 September 2017 Accepted: 12 December 2017

Published: 22 December 2017

Citation:

Liu X, Shen J, Fan D, Qiu X, Guo Q, Zheng K, Luo H, Shu J, Lu C,

Zhang G, LU A, Ma C and He X (2017) Yupingfeng San Inhibits NLRP3 Inflammasome to Attenuate the Inflammatory Response in Asthma Mice. Front. Pharmacol. 8:944. doi: 10.3389/fphar.2017.00944

\title{
Yupingfeng San Inhibits NLRP3 Inflammasome to Attenuate the Inflammatory Response in Asthma Mice
}

\author{
Xue Liu',2t, Jiawen Shen 1,2t, Danping Fan', Xuemei Qiu'1,2, Qingqing Guo ${ }^{1,3}$, \\ Kang Zheng ${ }^{1,3}$, Hui Luo ${ }^{1,2}$, Jun Shu4 ${ }^{4}$, Cheng Lu' ${ }^{1}$, Ge Zhang ${ }^{3}$, Aiping Lu ${ }^{3,5}$, Chaoying Ma ${ }^{2 \star}$ \\ and Xiaojuan $\mathrm{He}^{1,3 *}$
}

${ }^{1}$ Institute of Basic Research in Clinical Medicine, China Academy of Chinese Medical Sciences, Beijing, China, ${ }^{2}$ School of Life Sciences and Engineering, Southwest Jiaotong University, Chengdu, China, ${ }^{3}$ Law Sau Fai Institute for Advancing Translational Medicine in Bone and Joint Diseases, School of Chinese Medicine, Hong Kong Baptist University, Kowloon Tong, Hong Kong, ${ }^{4}$ Institute of Clinical Medical Sciences, China-Japan Friendship Hospital, Beijing, China, ${ }^{5}$ School of Basic Medical Sciences, Shanghai University of Traditional Chinese Medicine, Shanghai, China

Yupingfeng San (YPFS) is a representative Traditional Chinese Medicine (TCM) formula with accepted therapeutic effect on Asthma. However, its action mechanism is still obscure. In this study, we used network pharmacology to explore potential mechanism of YPFS on asthma. Nucleotide-binding oligomerization domain (NOD)-like receptor pathway was shown to be the top one shared signaling pathway associated with both YPFS and asthma. In addition, NOD-like receptor family pyrin domain-containing 3 (NLRP3) inflammasome was treated as target protein in the process of YPFS regulating asthma. Further, experimental validation was done by using LPS-stimulated U937 cells and ovalbumin (OVA)-sensitized BALB/c mice model. In vitro experiments showed that YPFS significantly decreased the production of TNF- $\alpha$ and IL-6, as well as both mRNA and protein levels of IL-1 $\beta$, NLRP3, Caspase-1 and ASC in LPS-stimulated U937 cells. In vivo experiment indicated that YPFS treatment not only attenuated the clinical symptoms, but also reduced inflammatory cell infiltration, mucus secretion and MUC5AC production in lung tissue of asthmatic mice. Moreover, YPFS treatment remarkably decreased the mRNA and protein levels of IL-1 $\beta$, NLRP3, Caspase- 1 and ASC in lung tissue of asthmatic mice. In conclusion, these results demonstrated that YPFS could inhibit NLRP3 inflammasome components to attenuate the inflammatory response in asthma.

Keywords: Yupingfeng San, asthma, network pharmacology, NLRP3 inflammasome, inflammation

\section{INTRODUCTION}

Asthma is a chronic inflammatory disorder of the airways in which many inflammatory cells play a role. This disease is characterized by recurrent episodes of wheezing, breathlessness, chest tightness and coughing (Braman, 2006; Mims, 2015). The cause of asthma is unknown, but it is generally thought that gene-environment interactions have played important roles in risk factors (Ober and Yao, 2011; Bonnelykke and Ober, 2016). Previous study revealed that genetic predisposition and 
environmental exposures were most likely to cause inflammation in the lower airway (Bunyavanich and Schadt, 2015). Current research showed that Nucleotide-binding oligomerization domain (NOD)-like receptor family pyrin domain-containing 3 (NLRP3), one of nucleotide-binding domain and leucine-rich repeat containing (NLR) family membranes, had a substantial impact on tissue inflammation including respiratory diseases like asthma and could aggravate the progress of asthma (Kufer and Sansonetti, 2011; Im and Ammit, 2014; Hosseinian et al., 2015). For this reason, NLRP3 inflammasome has been suggested as an important target for inflammatory disease control (Peng et al., 2016). In addition, it has been reported that NLRP3 inflammasome activation could lead to the increased release of interleukin (IL)-1 $\beta$ (Haneklaus and O'Neill, 2015). There's studies proved that NLRP3 mediated IL- $1 \beta$ could lead to a vicious cycle between previous and future exacerbations in asthma (Kim et al., 2017). For this reason, NLRP3 inflammasome and IL-1 $\beta$ have been suggested as important targets for inflammatory disease control (Fu et al., 2015; Peng et al., 2016).

Commonly, presently available drugs such as corticosteroids, biologic therapies have been found beneficial in controlling the asthma, but it had been proved with frequent side effects (Cooper et al., 2015). Yupingfeng San (YPFS), originally recorded in the book Danxi Xinfa, is a Chinese medicine formula consisting of Astragalus membranaceus, Atractylodes macrocephala, and Saposhnikoviae radix. YPFS has been found to have therapeutic effect on asthma and with less adverse reactions (Wang et al., 2013; Zhong et al., 2014; Chan et al., 2016). Modern pharmacological research indicated that YPFS could regulate the releases of cytokines, like IL- $1 \beta$, necrosis factor alpha (TNF)- $\alpha$ and IL-6 (Du et al., 2013). However, the underlying mechanism of YPFS on asthma is still unknown and further inquiry is needed.

Traditional Chinese Medicine (TCM) is well-known for its multi-component, multi-target and multi-pathway. And most diseases are not simply caused by one single factor. The TCM treatments can be visualized as a complexity against complexity paradigm between multi-target therapy such as TCM and the complex biological networks of human diseases (Li et al., 2014). As a major method, network pharmacology provide a method to unravel the complex and holistic mechanisms of TCM in treating complex diseases (Goh et al., 2007). Moreover, successful attempts on TCM study have been achieved in our group by network pharmacology analysis (Niu et al., 2015; Zhao et al., 2015; Fan et al., 2016). Therefore, in this study, we explored the underlying mechanism of YPFS on asthma via network pharmacology analysis and experimental validation.

\section{MATERIALS AND METHODS}

\section{Network Pharmacology Analysis}

Chemical compounds with $\mathrm{OB} \geq 30 \%$ or DL $\geq 0.18$ in Astragalus membranaceus, Atractylodes macrocephala, and Saposhnikoviae radix were obtained in Traditional Chinese Medicine Systems Pharmacology Database (TCMSP) ${ }^{1}$. Those compounds of the

\footnotetext{
${ }^{1}$ http://ibts.hkbu.edu.hk/LSP/tcmsp.php
}

three drugs were combined and repeated compounds were deleted. The corresponding target of each component was acquired in TCMSP database. The corresponding gene name of each target protein was obtained in UniProt database ${ }^{2}$ and non-human target proteins were excluded. Finally, the target protein regulating by YPFS was acquired. Asthmarelated human genes were searched on National Center for Biotechnology Information's (NCBI) Gene database ${ }^{3}$. Then, the target genes of YPFS and asthma were mapped. The interaction protein of mapped gene was obtained through the String interaction database $e^{4}$ and the protein interaction network was constructed. The pathway enrichment of the interaction protein was used the Database for Annotation, Visualization and Integrated Discovery (DAVID) $4^{5}$, and broad signaling pathways were eliminated. The top five pathways were extracted and the matching genes of the NOD-like receptor pathway which was ranked first were constructed the interaction network.

\section{Preparation of YPFS}

All crude drugs were purchased from Beijing Tongrentang. $60 \mathrm{~g}$ Astragalus membranaceus, $20 \mathrm{~g}$ Atractylodes macrocephala, and 20 g Saposhnikoviae radix were extracted twice with boiling water, each time $40 \mathrm{~min}$ (1:6 and 1:4, w/v) (Song et al., 2013). Concentrating the two filtrates liquid into extract with electric thermostatic water bath and then transferred to the vacuum oven for drying. After drying, the solid extract was crushed into powder and stored at $4^{\circ} \mathrm{C}$.

\section{Cell Culture}

Human leukemic U937 cells were purchased from American Type Culture Collection (Manassa, VA, United States), and were cultured at $37^{\circ} \mathrm{C}$ in a humidified atmosphere with $5 \%$ $\mathrm{CO}_{2}$ in RPMI 1640 medium (GIBCO, Gaithersburg, MD, United States) supplemented with 10\% fetal bovine serum (FBS) (GIBCO, Gaithersburg, MD, United States) and 1\% penicillinstreptomycin (PS) (GIBCO, Gaithersburg, MD, United States).

\section{Cell Viability Assay}

U937 cells were seeded at a density of $1.0 \times 10^{4}$ cells/well into a 96-well with RPMI 1640 containing 5\% FBS and 1\% PS at $37^{\circ} \mathrm{C}$ in a $5 \% \mathrm{CO}_{2}$ incubator. U937 were differentiated into macrophages by using phorbol 12-myristate 13-acetate (PMA) (Sigma, St. Louis, MO, United States) $(0.01 \mu \mathrm{g} / \mathrm{ml})$. After $48 \mathrm{~h}$, the cells were washed with phosphate-buffered saline solution (PBS) twice and incubated with YPFS $(0-100 \mu \mathrm{g} / \mathrm{ml})$ for $45 \mathrm{~h}$ at $37^{\circ} \mathrm{C}$ in a $5 \% \mathrm{CO}_{2}$ incubator. Cells were added with $10 \mu \mathrm{l} \mathrm{CCK}-8$ reagent (Dojindo, Tokyo, Japan) into each well and further cultured for $3 \mathrm{~h}$. The absorbance of each well was measured with a microplate reader (Bio-Tek Instruments, Winooski, VT, United States) at $450 \mathrm{~nm}$.

\footnotetext{
${ }^{2}$ http://www.uniprot.org/

${ }^{3}$ https://www.ncbi.nlm.nih.gov/genbank/

${ }^{4}$ https://string-db.org/

${ }^{5}$ https://david.ncifcrf.gov/
} 


\section{YPFS Treatment of U937 Cells}

U937 cells were plated in 6 well plates $\left(1 \times 10^{6}\right.$ cells/well $)$ and incubated with PMA for $48 \mathrm{~h}$ at $37^{\circ} \mathrm{C}, 5 \% \mathrm{CO}_{2}$. Then cells were washed for three times in PBS and induced with lipopolysaccharides (LPS) (Sigma, St. Louis, MO, United States) $(0.1 \mu \mathrm{g} / \mathrm{ml}, 2 \mathrm{~h})$. U937 cells were incubated with YPFS $(25 \mu \mathrm{g} / \mathrm{ml})$ for another $48 \mathrm{~h}$. INF39 (Selleck, Shanghai, China), a non-toxic, irreversible NLRP3 inhibitor able to decrease interleukin-1 $\beta$ release from macrophages, was used as the positive control at a concentration of $10 \mu \mathrm{M}$ (Cocco et al., 2017). The supernatant was collected to detect levels of IL- $1 \beta$, TNF- $\alpha$ and IL- 6 by ELISA and the cells were harvested to detect levels of NLRP3, ASC, Caspase- 1 and IL- $1 \beta$ with Real-Time PCR and western blotting.

\section{Animals}

Male BALB/c mice were purchased from Beijing Vital River Laboratory Animal Technology Co. Ltd., (Beijing, China), weighted 18-20 g with 7 weeks of age. The mice were bred in the China Academy of Chinese Medical Sciences [certification NO. SCXK (JING) 2016-0021] and housed in a room with a temperature-, humidity- and light-controlled environment. They were fed food and water ad libitum, and allowed to acclimatize themselves for 1 week before the initiation of experiment. The study was approved by the Research Ethics Committee of Institute of Basic Theory of Chinese Medicine, China Academy of Chinese Medical Sciences. All animals were treated in accordance with the guidelines and regulations for the use and care of animals of the Center for Laboratory Animal Care, China Academy of Chinese Medical Sciences.

\section{Induction of Asthma}

To establish an asthma model, $0.5 \mathrm{ml}$ mixture [10 $\mu \mathrm{g}$ ovalbumin (OVA), $2 \mathrm{mg}$ sodium hydroxide and $0.5 \mathrm{ml}$ saline] were injected on day 1 , day 7 , and day 14 for model group and administration group. The normal group was injected with the same amount of saline. From day 21, mice were sprayed with 1\% OVA solution once a day for $30 \mathrm{~min}$ and sprayed for 12 days. The normal group was sprayed with saline.

\section{Drug Treatments}

All the mice were divided into 4 groups: normal group, model group, dexamethasone (Dex) group $(1 \mathrm{mg} / \mathrm{kg} / \mathrm{d})$ and YPFS group $(13 \mathrm{~g} / \mathrm{kg} / \mathrm{d})$, each group contained 10 mice. The dose of Dex and YPFS were reference to related literature (Dong et al., 2012; Wang et al., 2013), and the administration start from the atomization period (day 21). In the $30 \mathrm{~min}$ before the atomization, the mice of the positive drug group were injected with $0.2 \mathrm{ml}$ of Dex. The mice in the administration group were given $0.5 \mathrm{ml}$ of YPFS solution, and the mice in the model group and the normal group were given $0.5 \mathrm{ml}$ of saline.

\section{Observation of Ethology}

The ethology of the mice was evaluated by observation of the following parameters: Fur luster, touching of nose and scratching of ears, irritability, sneezing, rapid breathing and incontinence (Jia et al., 2017).

\section{Histological Analysis}

Left lungs were removed from mice of each group, and distended with $10 \%$ buffered formalin. The tissues were sliced and embedded in paraffin, and $4 \mu \mathrm{m}$ sections were prepared for morphological evaluation with hematoxylin-eosin staining (HE) and for mucopolysaccharide staining with alcian blue-periodic acid-schiff (AB-PAS). Sections from all of the left lobes were examined blindly by three individuals. The scoring system for cell infiltration was as follows: 0 , no cells; 1 , a few cells; 2 , a ring of cells 1 cell layer deep; 3 , a ring of cells 2-4 cells deep; and 4 , a ring of cells $>4$ cells deep. Goblet cell hyperplasia in the airway epithelium was quantified based on a five-point system: 0 , no goblet cells; $1,<25 \%$ of the epithelium; $2,25-50 \%$ of the epithelium; $3,50-75 \%$ of the epithelium; and $4,>75 \%$ of the epithelium. Mean scores were calculated from ten mice (Underwood et al., 1995; Dong et al., 2012).

\section{Immunohistochemistry}

Paraffin sections were deparaffinized in 100\% xylene and rehydrated (100, 95, 90, 85, 80\% ethanol). Endogenous peroxidase activity was blocked by treating with $3 \%$ hydrogen peroxide $(10 \mathrm{~min})$ followed by a PBS wash twice $(5 \mathrm{~min}$ each). The sections were incubated with a MUC5AC antibody (Abcam, Cambridge, United Kingdom) at a 1:500 dilution in primary antibody dilution buffer (Beyotime, Shanghai, China) for $12 \mathrm{~h}$ at $4^{\circ} \mathrm{C}$. The sections were washed three times ( 3 min each) in PBS, incubated with SignalStain Boost ${ }^{\circledR}$ IHC Detection Reagent (HRP, Mouse) (Cell Signaling Technology, Beverly, MA, United States) for $30 \mathrm{~min}$ at room temperature, and washed in PBS for three times (5 min each). Secondary antibody was detected with SignalStain ${ }^{\circledR}$ DAB Substrate Kit (Cell Signaling Technology, Beverly, MA, United States) Slides were counterstained with hematoxylin (Leagene, Beijing, China) and mounted. To evaluate the protein expression, semi-quantitative image analysis was employed to measure the mean optical density (MOD) using Image-Pro Plus 6.0 software.

\section{Bronchoalveolar Lavage Fluid (BALF) Cell Count}

Bronchoalveolar lavage fluid was collected from the mice by endotracheal intubation using a catheter followed by lavage with $0.4 \mathrm{ml}$ of PBS for three times as previously described (Mi Chun et al., 2017). After lavage, approximately $1 \mathrm{ml}$ of BALF was recovered. Total BALF cells count was determined in a hemocytometer using trypan blue exclusion. Eosinophils, neutrophils, lymphocytes, and monocytes cell counts were determined in 300 BALF cells on cytospin smears of BAL samples from individual mice stained with Giemsa stain (Sigma, St. Louis, MO, United States).

\section{ELISA}

Cell supernatants were collected as well as serum in mice were prepared. The levels of IL-1 $\beta$, TNF- $\alpha$ and IL- 6 were detected by using commercially available ELISA kits (eBioscience, San Diego, CA, United States) according to the manufacturer's instructions. 


\section{Real Time-PCR}

The mRNA levels of IL-1 $\beta$, NLRP3, cysteinyl aspartate specific proteinase (Caspase)-1 and advanced synthesis and catalysis (ASC) were analyzed by RT-PCR. Total RNA of lung tissue was isolated using TaKaRa MiniBEST Universal RNA Extraction Kit (TaKaRa, Kusatsu, Japan) according to the manufacturer's instructions. This procedure was done under RNase-free conditions. The total RNA $(1 \mu \mathrm{g})$ was reverse transcribed to cDNA using PrimeScript ${ }^{\mathrm{TM}}$ RT reagent Kit with gDNA Eraser (TaKaRa, Kusatsu, Japan) according to the instruction manual. The specific transcripts were quantified by quantitative RT-PCR using SYBR ${ }^{\circledR}$ Premix Ex Taq ${ }^{\text {TM }}$ II (TliRNaseH Plus), ROX plus (TaKaRa, Kusatsu, Japan) and analyzed with ABI 7500 RT-PCR system (Applied Biosystems, Foster, CA, United States). Gene-specific primers were synthesized by Sangon Biotech (Shanghai, China) and the following primer sequences were used: CATGAGTGCTGCTTCGACAT (forward) and GCTTCAGTCCCACACACAGA (reverse) for H-NLRP3, CTGACGGATGAGCAGTACCA (forward) and AG TCCTTGCAGGTCCAGTTC (reverse) for H-ASC, GCTTT CTGCTCTTCCACACC (forward) and TCCTCCACATCACA GGAACA (reverse) for H-caspase-1, CCATGGACAAGCTGAG GAAG (forward) and GTGATCGTACAGGTGCATCG (reverse) for H-IL-1 $\beta$, TGGAGTCTACTGGCGTCTT (forward) and TGTCATATTTCTCGTGGTTCA (reverse) for H-GAPDH, GGAGGAAGAGGAGGAGGAAA (forward) and ACTGGAAG TGAGGTGGCTGT (reverse) for M-NLRP3, GGCTGCTGG ATGCTCTGTA (forward) and AGGCTGGTGTGAAACT GAAGA (reverse) for M-ASC, CAGACAAGGGTGCTGAACAA (forward) and TCGGAATAACGGAGTCAATCA (reverse) for M-Caspase-1, TGGCAATGAGGATGACTTGT (forward) and TGGTGGTCGGAGATTCGTA (reverse) for M-IL-1 $\beta$, AGGC CGGTGCTGAGTATGTC (forward) and TGCCTGCTT CACCACCTTCT (reverse) for M-GAPDH. The mRNA levels were normalized to GAPDH mRNA level. PCR conditions were shown as below: at $95^{\circ} \mathrm{C}$ for $30 \mathrm{~s}, 40$ cycles at $95^{\circ} \mathrm{C}$ for $5 \mathrm{~s}$ and at $60^{\circ} \mathrm{C}$ for $30 \mathrm{~s}$. Relative mRNA expression was calculated by comparative CT method.

\section{Western Blotting}

The levels of NLRP3, ASC, Caspase- 1 and IL-1 $\beta$ in mice were detected by western blotting. Tissue homogenates were prepared in lysis buffer (Beyotime, Shanghai, China), consisting of $1 \mathrm{nM}$ phenylmethanesulfonyl fluoride (PMSF) (Beyotime, Shanghai, China). Proteins were denatured and equal amounts of proteins were electrophoresed in $12 \%$ bis-Tris/polyacrylamide gels (Beyotime, Shanghai, China) and transferred to Polyvinylidene fluoride (PVDF) (Amresco, Houston, TX, United States). Membranes with $0.45 \mu \mathrm{m}$ pore-size Millipore filter. The membranes were blocked for $2 \mathrm{~h}$ in blocking solution (TBST containing 5\% skim milk powder and $0.1 \%$ Tween 20) and incubated overnight at $4^{\circ} \mathrm{C}$ with anti-NLRP3, anti-Caspase-1, anti-IL-1 $\beta$ antibody (Abcam, Cambridge, United Kingdom) at 1:1000 and anti-ASC antibody (Abcam, Cambridge, United Kingdom) at 1:500 in TBST containing 5\% bovine sera albumin. After that, incubation with horseradish peroxidase-conjugated secondary antibody (1:10000 dilution in TBST containing 5\% skim milk powder) was performed at room temperature for $2 \mathrm{~h}$, and immunoreactivity was detected by using enhanced chemiluminescence (APPLYGEN, Beijing, China). Blots were scanned and analyzed for measurement of the band intensities with UN-SCAN-IT version 5.1 software. Band intensity was calculated as follows: band intensity $=$ sum of all pixel values in the segment selected-background pixel value in that segment.

\section{Statistical Analysis}

Data were expressed as the mean \pm SD of triplicate experiments and analyzed with SPSS version 17.0 software (SPSS Inc., Chicago, IL, United States). Statistically significant values were determined using ANOVA and Dunnett's post hoc test, and $p$-values of less than 0.05 were considered statistically significant.

\section{RESULTS}

\section{YPFS Might Treat Asthma by Regulating the Expression of NLRP3 Inflammasome}

Two hundred and thirty chemical compounds (Supplementary Tables 1-3), 372 human target proteins (Supplementary Table 4) and 793 asthma-related human genes (Supplementary Table 5) of YPFS were obtained in this study. The reaction network that YPFS antagonized asthma was built through String database (Supplementary Figure 1). DAVID database pathway enrichment analysis showed that the top five pathways of YPFS regulating asthma were NOD-like receptor signaling pathway, tumor necrosis factor (TNF) signal pathway, phosphatidylinositol-3kinase (PI3K)-AKT signal pathway, Hypoxia-inducible factor (HIF)-1 signal pathway and nuclear factor-kappaB (NF- $\kappa \mathrm{B}$ ) signal pathway (Table 1). Using the String database to visualize the matching gene of the NOD-like receptor pathway, we found that the NLRP3 inflammasome might play an important role in the process that YPFS regulating the asthma (Figure 1).

\section{YPFS Inhibited the Increase of Inflammatory Cytokines in LPS-Stimulated U937 Cells}

Our results showed that YPFS didn't exhibit obvious cytotoxicity at the concentration of $0,3.125,6.2512 .5$ and $25 \mu \mathrm{g} / \mathrm{ml}(P>0.05)$ (Figure 2A). Subsequently, $25 \mu \mathrm{g} / \mathrm{ml}$ YPFS was used for the

TABLE 1 | Top 5 shared signaling pathways of YPFS and asthma.

\begin{tabular}{llcc}
\hline Pathway ID & Pathway description & $\begin{array}{c}\text { False } \\
\text { discovery rate }\end{array}$ & $\begin{array}{c}\text { Observed } \\
\text { gene count }\end{array}$ \\
\hline 4621 & $\begin{array}{l}\text { NOD-like receptor signaling } \\
\text { pathway }\end{array}$ & $1.69 \mathrm{E}-19$ & 16 \\
4668 & TNF signaling pathway & $2.00 \mathrm{E}-16$ & 17 \\
4151 & PI3K-Akt signaling pathway & $3.85 \mathrm{E}-15$ & 24 \\
4066 & HIF-1 signaling pathway & $9.63 \mathrm{E}-13$ & 14 \\
4064 & NF-KB signaling pathway & $2.32 \mathrm{E}-12$ & 13
\end{tabular}




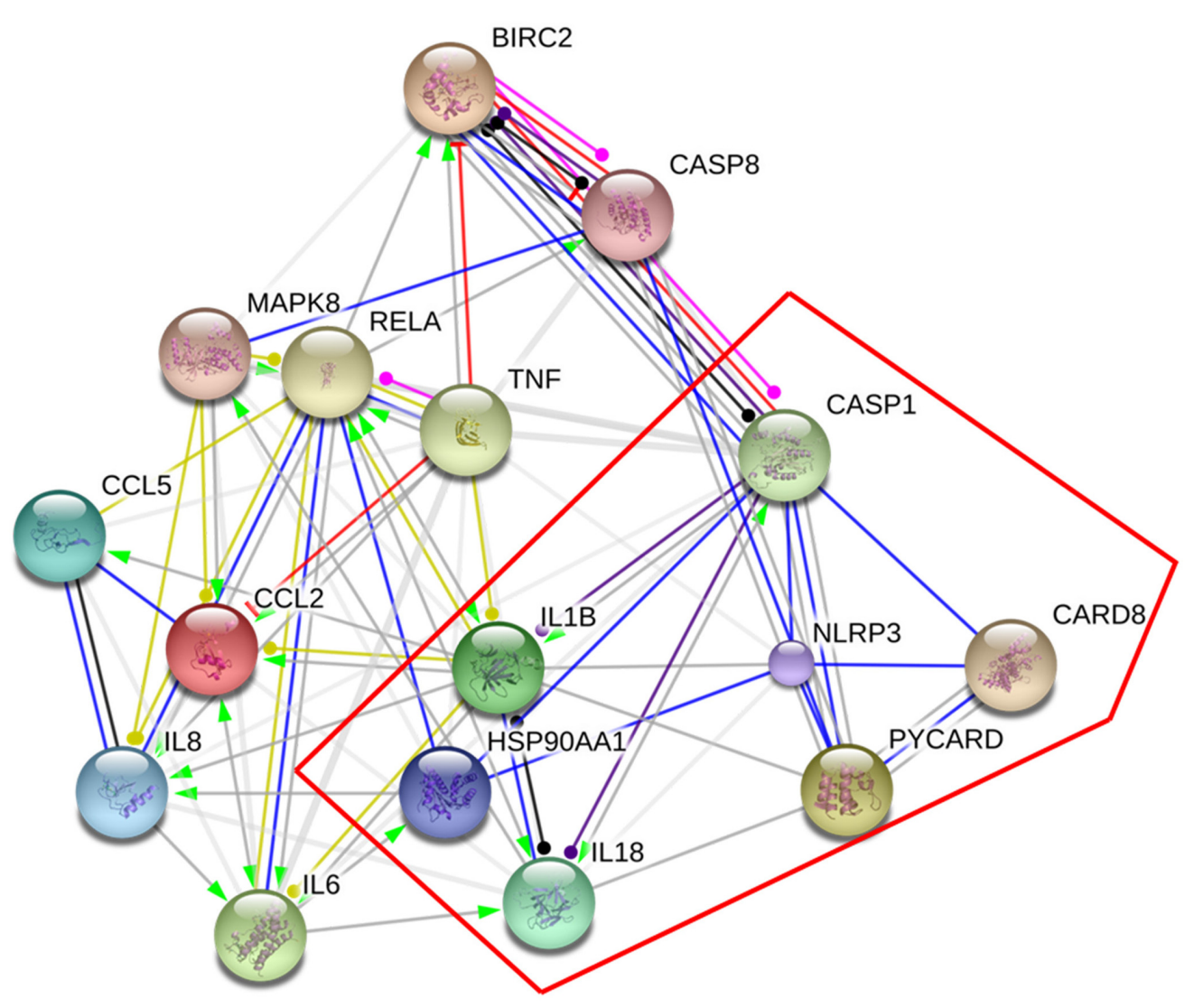

FIGURE 1 | Target genes of YPFS treating asthma. The genes in the red box were the key genes of NLRP3 inflammasome.

further experiments. As shown in Figures 2B,C, We found that cytokine production in supernatant were all significantly increased in the LPS stimulation group compared to the control group $(P<0.01)$. YPFS treatment was able to interfere TNF- $\alpha$ and IL- 6 production, which was shown by lower levels of TNF- $\alpha$ and IL-6 than the LPS stimulation group $(P<0.01)$.

\section{YPFS Reduced the Levels of NLRP3 Inflammasome Relative Genes and Proteins in LPS-Stimulated U937 Cells}

To investigate whether YPFS regulate the expression of NLRP3 inflammasome, we detected the levels of NLRP3 inflammasome relative components. As shown in Figure 3, compared to the normal group, LPS stimulation significantly increased NLRP3, caspase-1 and ASC levels both at mRNA and protein levels $(P<0.01)$. Both YPFS and INF39 could significantly inhibit the mRNA and protein levels of NLRP3 inflammasome components compared to LPS stimulation group $(P<0.05$ or $P<0.01)$.

\section{YPFS Inhibited the Production of IL-1 $\beta$ in LPS-Stimulated U937 Cells}

Compared to the normal group, LPS stimulation significantly increased IL-1 $\beta$ production (Figure 4). Both YPFS and
INF39 could significantly inhibit the IL-1 $\beta$ production in the cell supernatants (Figure 4A). The mRNA (Figure 4B) and protein levels (Figures 4C,D) of IL-1 $\beta$ in LPSstimulated U937 cells were also remarkably decreased $(P<0.01)$.

\section{YPFS Ameliorated Lung Inflammation, Mucus Secretion and MUC5AC Production in Asthma Mice}

In order to verify the therapeutic effect of YPFS on asthma, OVAsensitized asthma model was constructed. After sensitization, mice in model group showed obvious symptoms of nose touching and ear scratching, irritability, sneezing, rapid breathing and incontinence, while these symptoms were all improved after using YPFS. As shown in Figures 5A,D, OVA induction caused the infiltration of inflammatory cells which were mainly eosinophils into the perivascular connective tissues and peribronchiolar compared with the normal group. YPFS significantly attenuated the eosinophil-rich infiltration compared with the model group. To further determine the effect of YPFS on mucus secretion, adjacent lung sections were stained with AB-PAS (Figures 5B,E). There was marked goblet cell hyperplasia and mucus hypersecretion within the bronchi in the mice lungs from the model group 

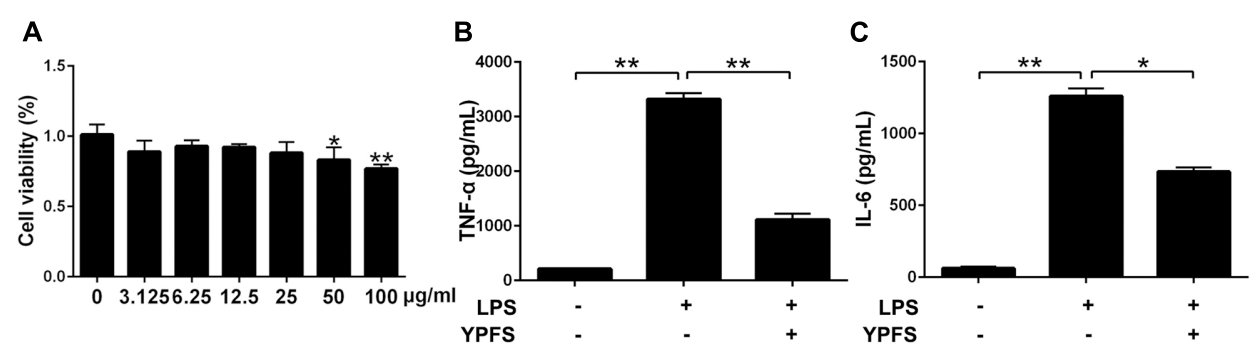

FIGURE 2 | Yupingfeng San inhibited the increase of inflammatory cytokines in LPS-stimulated U937 cells. (A) Effect of YPFS on cell viability of U937 was detected by CCK-8 reagent. The OD values were measured at $450 \mathrm{~nm}$. Cell supernatants were collected for ELISA detection. The levels of TNF- $\alpha$ (B) and IL-6 (C) were shown as above. ${ }^{*} P<0.05,{ }^{* *} P<0.01$, compared with the model group.

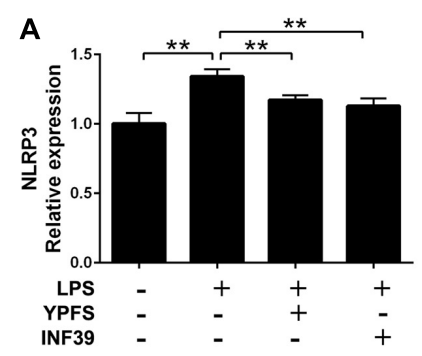

D

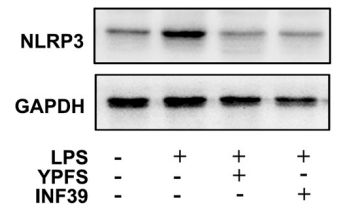

$\mathbf{G}$

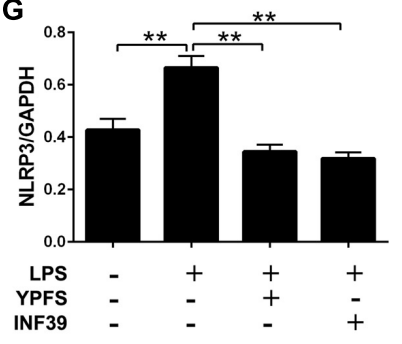

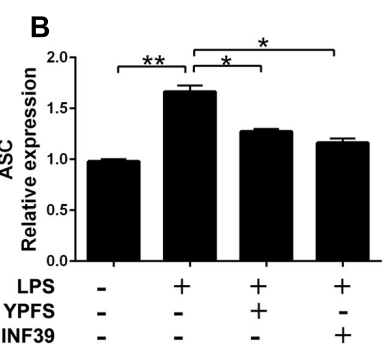

E
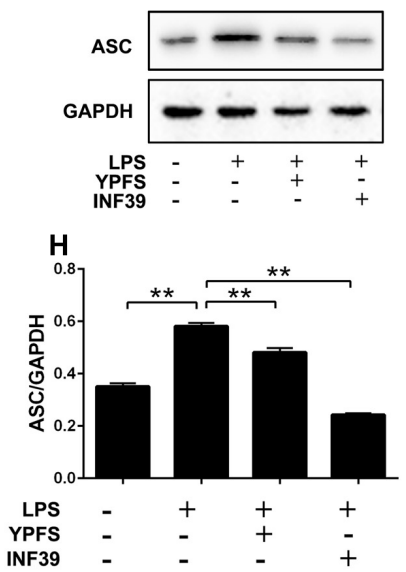

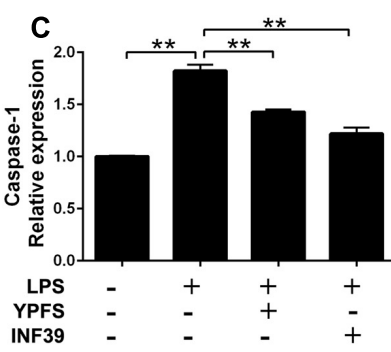

$\mathbf{F}$
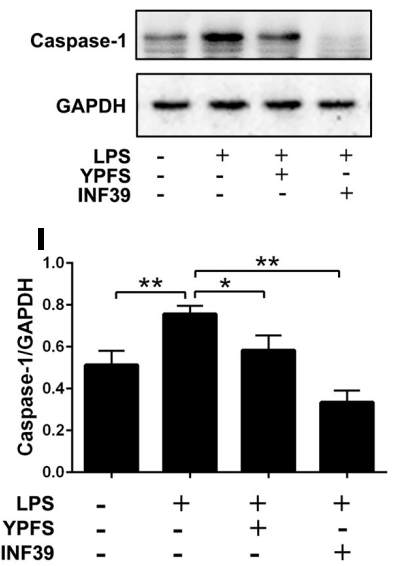

FIGURE 3 | Yupingfeng San reduced the expression of NLRP3 Inflammasome in LPS-stimulated U937 cells. Cells were pre-treated with PMA for 48 h and then incubated with LPS for $2 \mathrm{~h}$. Subsequently, cells were stimulated with YPFS. INF39 was used as the positive control. After $48 \mathrm{~h}$, cells were collected. (A-C) The mRNA levels of NLRP3, ASC and Caspase-1 were detected by real time-PCR. (D-I) The protein levels of NLRP3, ASC and Caspase-1 were detected by western blotting, and the ratio of NLRP3/GAPDH, ASC/GAPDH and Caspase-1/GAPDH were shown. ${ }^{*} P<0.05,{ }^{* *} P<0.01$, compared with model group.

but not in the lungs from the normal group. Treatment with YPFS markedly attenuated the OVA-induced mucus secretion. MUC5AC is a major mucin protein secreted from the airway surface epithelium and played important role in asthma (Tan et al., 2011). To further confirm the effect of YPFS on asthma, histological sections of lung tissue were stained immunohistochemically to detect MUC5AC level. Our studies have proved that MUC5AC expression was markedly upregulated in lung tissue from OVA-induced asthmatic mice. Compared with normal group, MUC5AC were significantly increased in the stained sections of model groups. When compared with the model group, MUC5AC were significantly less in the stained sections of Dex group and YPFS group (Figures 5C,F).

\section{YPFS Decreased Inflammatory Cell Numbers in BALF}

To determine the effect of YPFS on inflammatory cell infiltration in the lungs of asthmatic mice, the total numbers of inflammatory cells in the BALF of the YPFS-treated and untreated asthmatic mice were determined. Compared with the normal mice, mice in model group had significantly increased numbers of total inflammatory cells. By comparison, the YPFS- and Dex-treated 

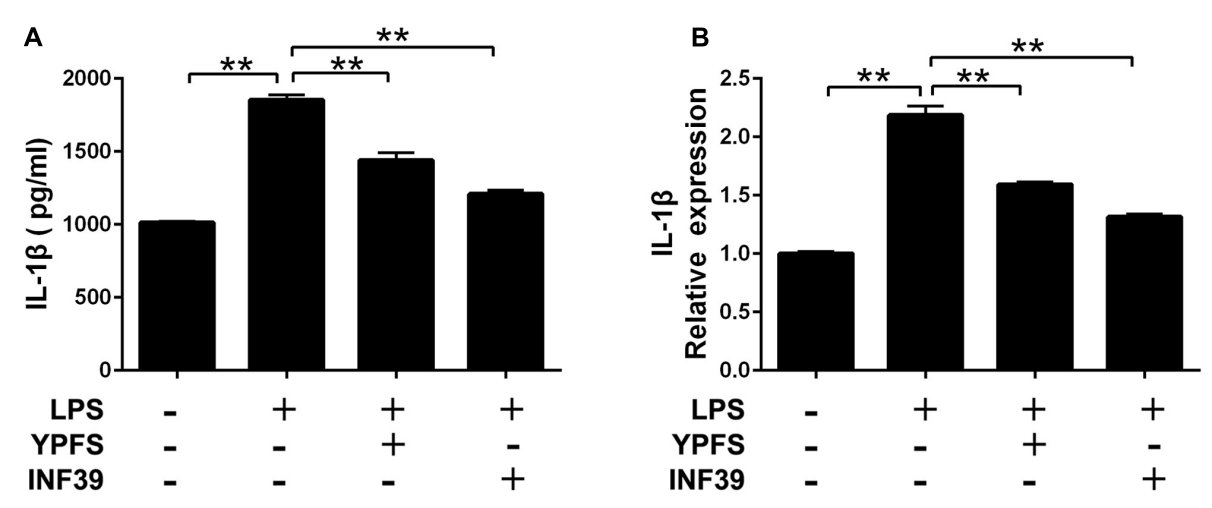

C

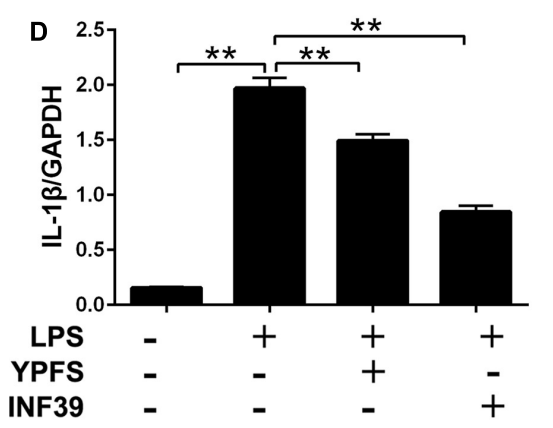

FIGURE 4 | Yupingfeng San inhibited the production of IL-1 $\beta$ in LPS-stimulated U937 cells. (A) The level of IL-1 $\beta$ in cell supernatant was evaluated by ELISA. (B) The mRNA level of IL-1 $\beta$ in cells was assessed by real time-PCR. (C,D) The protein level of IL-1 $\beta$ in cells was detected by Western blotting. ** $P<0.01$, compared with model group.

mice had significantly fewer inflammatory cells in their BALF (Table 2). Analysis of the numbers of different inflammatory cells (eosinophils, neutrophils, macrophages, and lymphocytes) in the BALF showed that model group had very high numbers of eosinophils. Compared with model group, the YPFS-treated asthmatic mice had significantly fewer inflammatory cells, particularly eosinophils (Table 2).

\section{YPFS Reduced Pro-inflammatory Cytokines Expression in Serum of Asthma Mice}

To observe the effects of YPFS on production of proinflammatory cytokines in OVA-sensitized asthma mice, the expression of TNF- $\alpha$ and IL- 6 in serum of OVA-sensitized asthma mice were examined by ELISA. Our results showed that levels of TNF- $\alpha$ and IL- 6 in model group were all elevated. However, these effects were attenuated by YPFS treatment (Figure 6).

\section{YPFS Inhibited the Expression of NLRP3 Inflammasome in OVA-Sensitized Asthma Mice}

To further examine the mechanism of YPFS on OVA-sensitized asthma model, NLRP3 inflammasome level in lung tissues of mice in each group was detected. The results of RT-PCR showed that the mRNA levels of NLRP3, ASC and Caspase-1 in lung tissue was dramatically decreased after YPFS treatment compared to the model group (Figures 7A-C). Meanwhile, the protein levels of NLRP3, ASC, Caspase-1 and Pro-Caspase-1 in lung tissue of YPFS treated OVA-sensitized asthma mice also decreased significantly in comparison with those in model group (Figures 7D-J).

\section{YPFS Inhibited the Expression of IL-1 $\beta$ in OVA-Sensitized Asthma Mice}

NLRP3 inflammasome activation could cause excessive IL-1 $\beta$ activation (Menu and Vince, 2011). To further verify the effects of YPFS on production of IL- $1 \beta$, the level of IL- $1 \beta$ in serum was detected. As shown in Figure 8A, the level of IL-1 $\beta$ in the serum of model group was significantly higher than those in normal group. In contrast, higher level of IL- $1 \beta$ was significantly inhibited by YPFS treatment. As the level of IL-1 $\beta$ in serum was suppressed by YPFS, we wondered whether it could also be inhibited in the injured lung. As shown in Figures 8B-D, the mRNA and protein levels of IL-1 $\beta$ in the lung from model group were apparently raised compared to normal group, which was significantly decreased by YPFS treatment.

\section{DISCUSSION}

Yupingfeng San is widely used to treat the diseases of respiratory systems and immune systems, especially asthma 


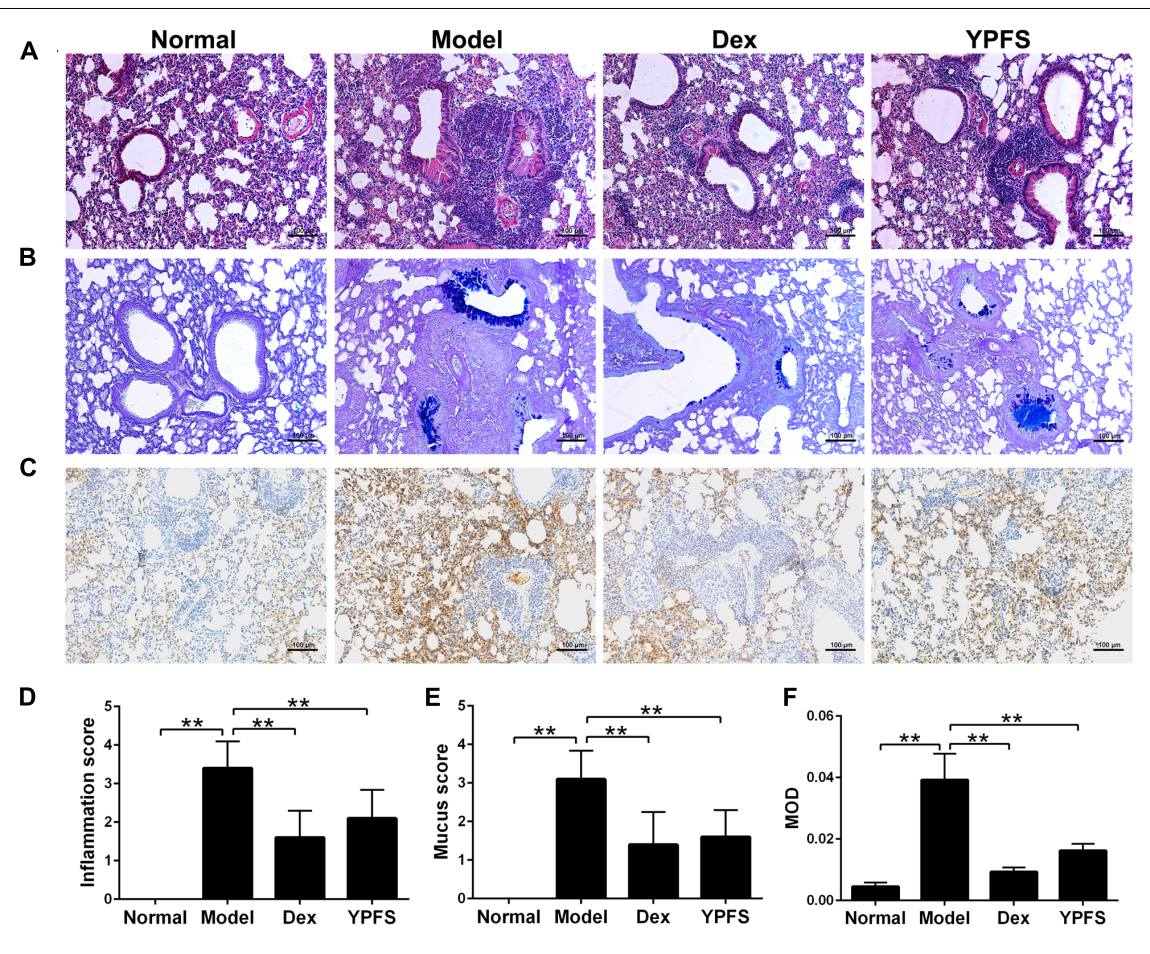

FIGURE 5 | Yupingfeng San ameliorated lung inflammation, mucus secretion and reduced MUC5AC in asthma mice. Asthma model was induced by OVA-sensitized $\mathrm{BALB} / \mathrm{c}$ mice. From the start of the atomization period, YPFS intragastric administration or dexamethasone (Dex) injection was carried out. (A) The upper lobe of left lungs was collected and the histopathological changes of the lung tissue were observed by HE staining. (B) The mucus secretion in the bronchus was observed by AB-PAS staining. (C) Immunohistochemical staining for MUC5AC. Tissue sections from lungs in each group were stained with monoclonal MUC5AC antibody. (D-F) The inflammation score, mucus secretion score and MOD in each group were shown. MOD: mean optical density. All the images are shown at $100 \times$ magnification. ${ }^{* *} P<0.01$, compared with the model group.

TABLE 2 | Effect of YPFS on bronchoalveolar lavage differential cell counts.

\begin{tabular}{|c|c|c|c|c|c|}
\hline & Total cells $\left(\times 10^{3}\right)$ & Eosinophils $\left(\times 10^{3}\right)$ & Neutrophils $\left(\times 10^{3}\right)$ & Lymphocytes $\left(\times 10^{3}\right)$ & Macrophage $\left(\times 10^{3}\right)$ \\
\hline Normal & $50.71 \pm 9.65$ & $0.43 \pm 0.17$ & $0.53 \pm 0.09$ & $0.29 \pm 0.06$ & $48.46 \pm 9.43$ \\
\hline Model & $371.54 \pm 60.98^{\# \#}$ & $117.91 \pm 54.79^{\# \#}$ & $5.48 \pm 0.95^{\# \#}$ & $5.97 \pm 1.09^{\# \#}$ & $241.32 \pm 21.75^{\# \#}$ \\
\hline Dex & $200.31 \pm 56.91^{* *}$ & $59.36 \pm 27.78^{*}$ & $2.56 \pm 1.08^{* *}$ & $2.97 \pm 1.51^{* *}$ & $110.27 \pm 49.31^{* *}$ \\
\hline YPFS & $263.66 \pm 63.93^{* *}$ & $71.89 \pm 26.51^{*}$ & $3.29 \pm 1.85^{* *}$ & $3.96 \pm 1.46^{* *}$ & $183.51 \pm 38.67^{* *}$ \\
\hline
\end{tabular}

${ }^{\#} P<0.01$, compared with the normal group. ${ }^{*} P<0.05,{ }^{* *} P<0.01$, compared with the model group.
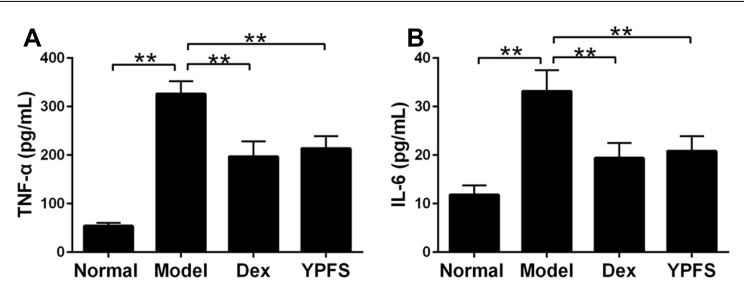

FIGURE 6 | Yupingfeng San reduced pro-inflammatory cytokines expression in serum of asthma mice. Mice were sacrificed and the serum was collected for ELISA detection. The levels of TNF- $\alpha$ (A) and IL-6 (B) were shown as above. ${ }^{* *} P<0.01$, compared with the model group.

(Li et al., 2013; Wang et al., 2013; Chan et al., 2016). In a previous clinical trial, patients' cardinal symptoms of asthma were found reduced markedly after treated with YPFS
(Chen et al., 2014). Previous studies also found YPFS had anti-inflammatory effect and this effect was achieved through suppressing the transcript and protein expressions of proinflammatory cytokine (Du et al., 2013; Sun et al., 2017). Consistent with previous researches, our study confirmed the therapeutic effect of YPFS on asthma. It could improve the symptoms of asthma mice like, nose touching, ear scratching, irritability, sneezing, rapid breathing and incontinence. After treating with YPFS, inflammatory cell infiltration, mucus secretion and MUC5AC expression in lungs of asthmatic mice were significantly inhibited. It also decreased inflammatory cell numbers in BALF and TNF- $\alpha$, IL- 6 levels in asthmatic mice plasma.

Although lots of researches had confirmed the efficacy of YPFS, more mechanisms by which YPFS inhibit inflammatory response should be fully elucidated (Chen et al., 2014; Song et al., 2016). In this study, we used network pharmacological 

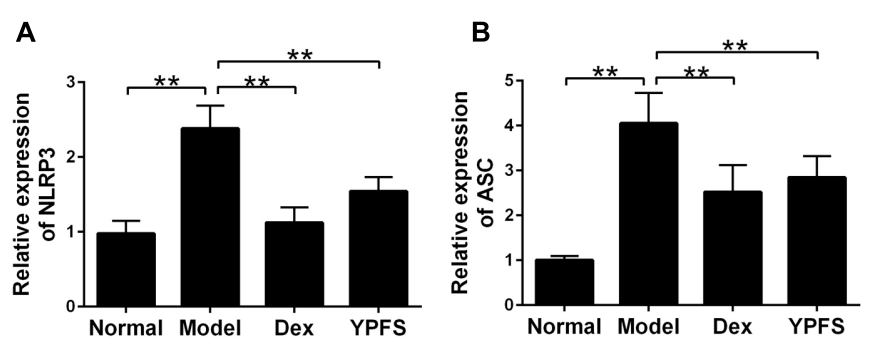

C

D

\section{E}
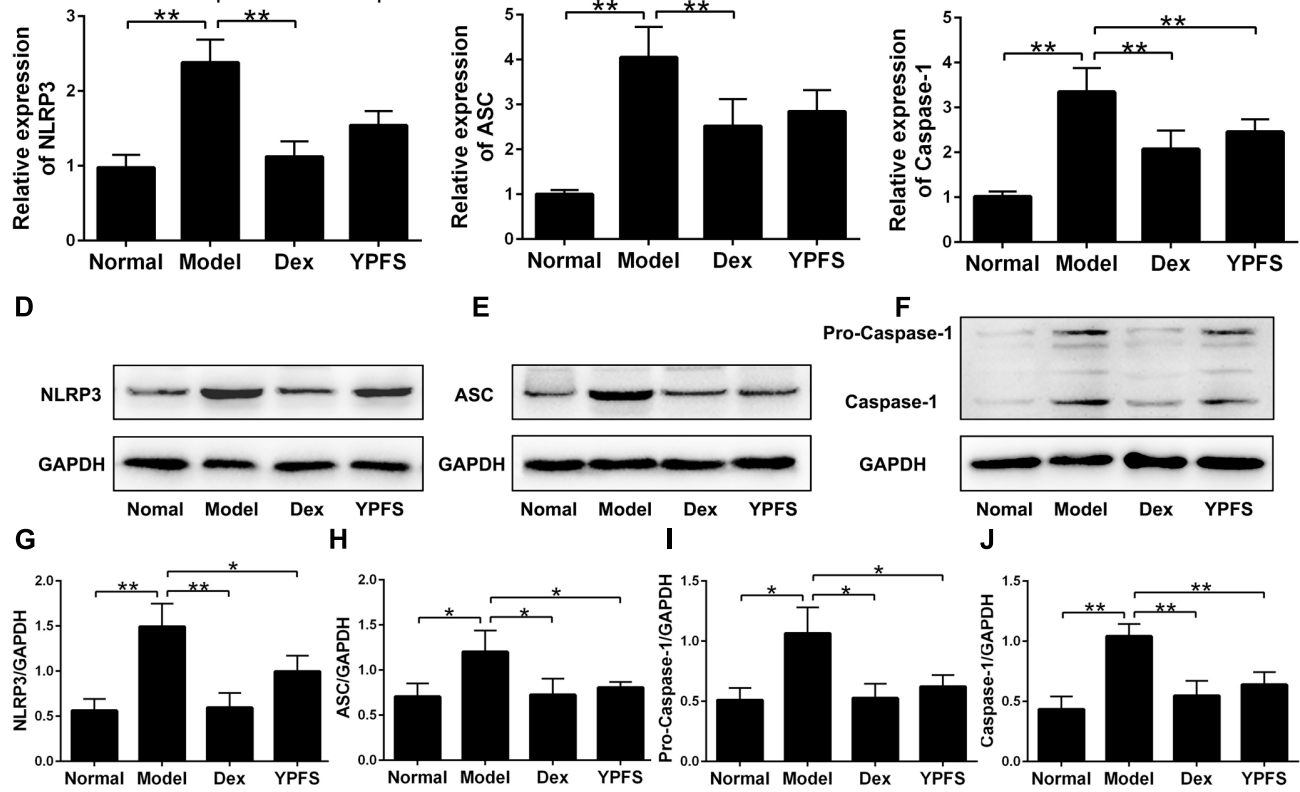

FIGURE 7 | Yupingfeng San inhibited the expression of NLRP3 inflammasome in OVA-sensitized asthma mice. After mice were sacrificed, the upper lobe of the right lung was collected for RT-PCR and western blotting detection. (A-C) The mRNA levels of NLRP3, ASC and Caspase-1 on the upper lobe of the right lung were detected by RT-PCR. (D-J) The protein levels of NLRP3, ASC, Caspase-1 and Pro-Caspase-1 were detected by western blotting, and the ratio of NLRP3/GAPDH, ASC/GAPDH, Caspase-1/GAPDH and Pro-Caspase-1/GAPDH were shown. ${ }^{*} P<0.05,{ }^{* *} P<0.01$, compared with the model group.
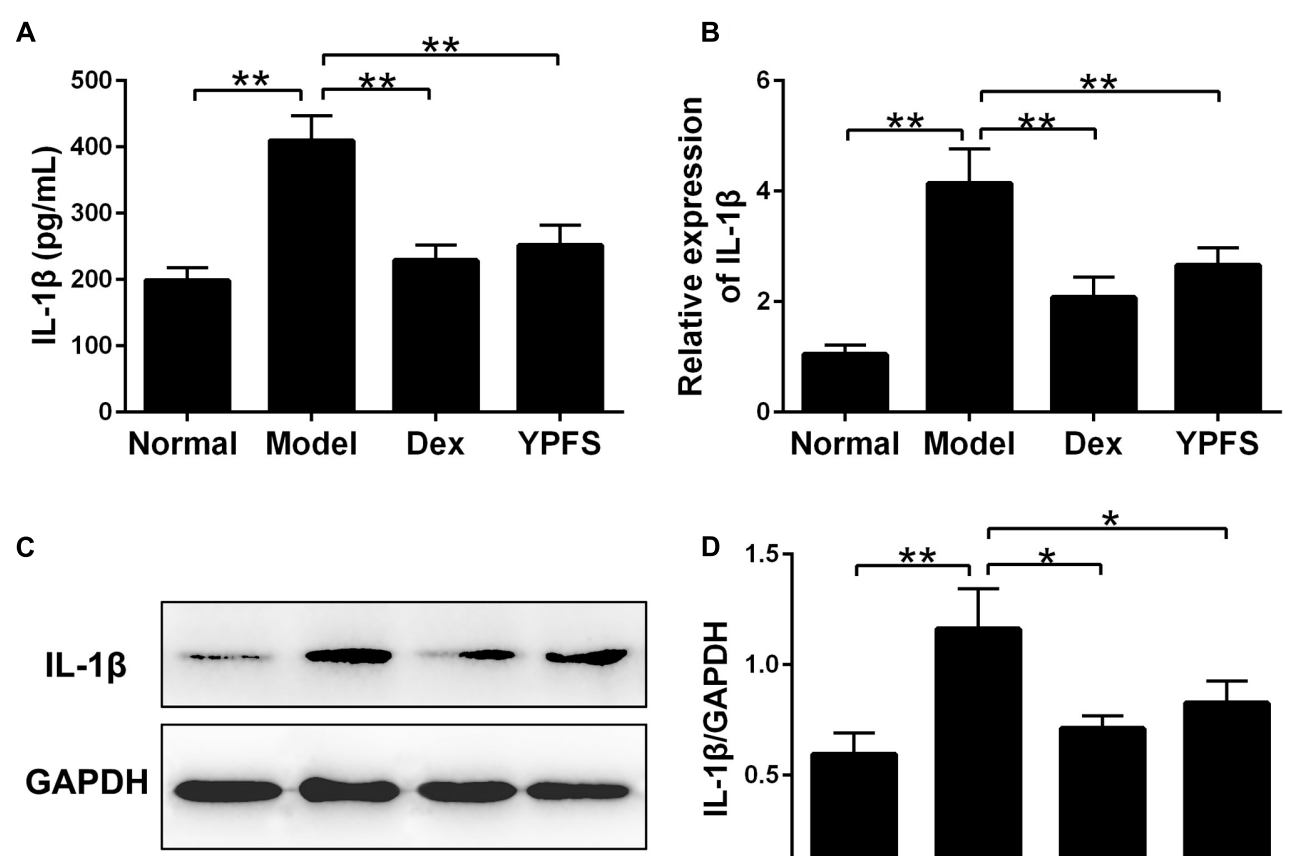

Nomal Model Dex YPFS

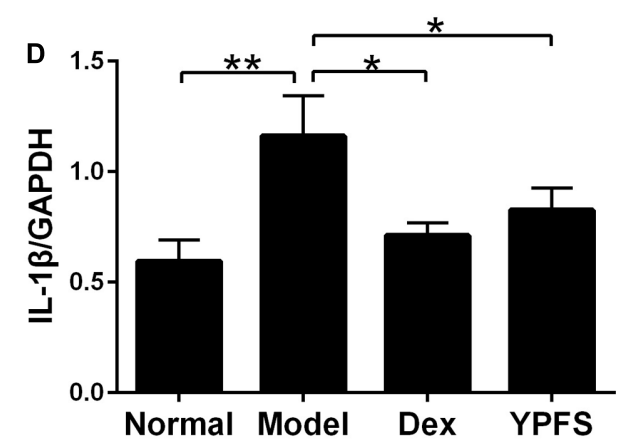

FIGURE 8 | Yupingfeng San inhibited the expression of IL-1 $\beta$ in OVA-sensitized asthma mice. (A) The level of IL-1 $\beta$ in the serum was detected by ELISA. (B) The mRNA level of IL-1 $\beta$ on the upper lobe of the right lung was detected by RT-PCR. (C,D) The protein level of IL-1 $\beta$ was detected by western blotting and the ratio of IL-1 $\beta$ /GAPDH was shown. $* P<0.05,{ }^{* *} P<0.01$, compared with the model group. 
analysis to investigate the mechanisms of YPFS acting on asthma. Our analysis indicated that multiple pathways were closely associated with asthma, such as TNF signaling pathway, PI3KAkt signaling pathway, HIF-1 signaling pathway, and NF-кB signaling pathway. And these findings were consistent with previous studies (Crotty Alexander et al., 2013; Li et al., 2015, 2016; Schuliga, 2015; Peng et al., 2016). In addition, we found that NOD-like receptor signaling pathway was the top one shared signaling pathway of YPFS and asthma, which was not explored before. Studies on NOD-like receptor signaling pathways revealed that NLRP3, composed by NLRP3, ASC and Caspase-1, could be a very important immune receptor responsible for auto-inflammatory response (Martinon et al., 2009), and when excessive activated, NLRP3 inflammasome could lead to serious inflammatory conditions (Latz et al., 2013). Moreover, previous clinical and experimental studies demonstrated that the expression of NLRP3 inflammasome was up-regulated in patients with asthma and OVA-induced asthma model (Kim et al., 2017; Rossios et al., 2017), which indicated NLRP3 inflammasome played an important role in the pathology of asthma (Simpson et al., 2014). Our results showed that mRNA and protein levels of NLRP3, ASC and Caspase-1 in LPS-stimulated U937 cells as well as lung tissues of OVAinduced asthma mice were dramatically decreased after YPFS treatment, which suggested YPFS could inhibit the inflammatory response in OVA-induced asthma through suppressing the NLRP3 inflammasome.

In addition, more evidences implicated NLRP3 inflammasome activation could lead to the increased release of IL-1 $\beta$ (Negash et al., 2013; Kim et al., 2017). And this conclusion was also confirmed in patients with asthma (Simpson et al., 2014). Further research revealed that NLRP3 inflammasomemediated IL- $1 \beta$ might be one of the key factors which could induce inflammation and result in asthma, and increasing IL-1 $\beta$ could also be seen as a marker of asthma (Kim et al., 2015; Giuffrida and Valero, 2017). Therefore, targeting elevated IL-1 $\beta$ instead of using corticosteroids might be an effective treatment for asthma. In this study, the expression of IL-1 $\beta$ in LPS-stimulated U937 Cells, in serum and in the lung tissue of asthma mice was all detected. We found that YPFS not only significantly inhibited the IL- $1 \beta$ production in vitro, but also decreased its levels in the periphery and lung tissue of OVA-induced asthma mice. These data indicated YPFS could inhibit inflammatory response in asthma through modulating NLRP3 inflammasome and subsequently downregulating IL-1 $\beta$.

In this study, we provided an integrative analysis by combining network pharmacology prediction with experiment validation to understand the pharmacological mechanism of YPFS acting on asthma. Furthermore, our finding also

\section{REFERENCES}

Bonnelykke, K., and Ober, C. (2016). Leveraging gene-environment interactions and endotypes for asthma gene discovery. J. Allergy Clin. Immunol. 137, 667-679. doi: 10.1016/j.jaci.2016.01.006 demonstrated that network pharmacology was a fairly reliable way to find TCM's target and possible mechanisms.

\section{CONCLUSION}

Our data in this research demonstrated that YPFS could attenuate inflammatory response in asthma through suppressing the NLRP3 inflammasome.

\section{ETHICS STATEMENT}

Full name of the ethics committee that approved the study. The study was approved by the Research Ethics Committee of Institute of Basic Theory of Chinese Medicine, China Academy of Chinese Medical Sciences. Consent procedure used for human participants or for animal owners. Male BALB/c mice were purchased from Beijing Vital River Laboratory Animal Technology Co. Ltd., weighted 18-20 g with 7 weeks of age. The mice were bred and housed in a room with a temperature-, humidity- and light-controlled environment. They were fed food and water ad libitum, and allowed to acclimatize themselves for 1 week before the initiation of experiment. Any additional considerations of the study in cases where vulnerable populations were involved, for example minors, persons with disabilities or endangered animal species.

\section{AUTHOR CONTRIBUTIONS}

$\mathrm{XL}$ and JS performed the major research in equal contribution. DF, XQ, QG, KZ, HL, JS, CL, GZ, and AL provided the technical support. CM contributed to final approval of the version to be published. $\mathrm{XH}$ designed the study and revised the manuscript.

\section{ACKNOWLEDGMENTS}

This study was supported by the research funding from Ministry of Sciences and Technology of China (No. 2014DFG32700) and Hong Kong Baptist University Strategic Development Fund (SDF15-0324-P02(b)).

\section{SUPPLEMENTARY MATERIAL}

The Supplementary Material for this article can be found online at: https://www.frontiersin.org/articles/10.3389/fphar. 2017.00944/full\#supplementary-material

Braman, S. S. (2006). The global burden of asthma. Chest 130, 4s-12s. doi: 10.1378/ chest.130.1_suppl.4S

Bunyavanich, S., and Schadt, E. E. (2015). Systems biology of asthma and allergic diseases: a multiscale approach. J. Allergy Clin. Immunol. 135, 31-42. doi: 10.1016/j.jaci.2014.10.015 
Chan, P. H., To, C. Y., Chan, E. Y., Li, H., Zhang, X., Chow, P. Y., et al. (2016). A randomized placebo-controlled trial of traditional Chinese medicine as an add-on therapy to oral montelukast in the treatment of mild persistent asthma in children. Complement. Ther. Med. 29, 219-228. doi: 10.1016/j.ctim.2016. 10.010

Chen, X. H., Li, H. J., Zhang, P. H., Zhang, H. H., and Guo, H. Y. (2014). Treating chronic persistent bronchial asthma children with abnormal myocardial enzyme spectrum by Yupingfeng powder: an efficacy observation. Zhongguo Zhong Xi Yi Jie He Za Zhi 34, 518-521.

Cocco, M., Pellegrini, C., Martinez-Banaclocha, H., Giorgis, M., Marini, E., Costale, A., et al. (2017). Development of an acrylate derivative targeting the NLRP3 inflammasome for the treatment of inflammatory bowel disease. J. Med. Chem. 60, 3656-3671. doi: 10.1021/acs.jmedchem.6b01624

Cooper, V., Metcalf, L., Versnel, J., Upton, J., Walker, S., and Horne, R. (2015). Patient-reported side effects, concerns and adherence to corticosteroid treatment for asthma, and comparison with physician estimates of side-effect prevalence: a UK-wide, cross-sectional study. NPJ Prim. Care Respir. Med. 25:15026. doi: 10.1038/npjpcrm.2015.26

Crotty Alexander, L. E., Akong-Moore, K., Feldstein, S., Johansson, P., Nguyen, A., McEachern, E. K., et al. (2013). Myeloid cell HIF-1alpha regulates asthma airway resistance and eosinophil function. J. Mol. Med. 91, 637-644. doi: 10.1007/s00109-012-0986-9

Dong, C., Wang, G., Li, B., Xiao, K., Ma, Z., Huang, H., et al. (2012). Anti-asthmatic agents alleviate pulmonary edema by upregulating AQP1 and AQP5 expression in the lungs of mice with OVA-induced asthma. Respir. Physiol. Neurobiol. 181, 21-28. doi: 10.1016/j.resp.2011.12.008

Du, C. Y., Choi, R. C., Zheng, K. Y., Dong, T. T., Lau, D. T., and Tsim, K. W. (2013). Yu Ping Feng San, an ancient Chinese herbal decoction containing Astragali Radix, Atractylodis Macrocephalae Rhizoma and Saposhnikoviae Radix, regulates the release of cytokines in murine macrophages. PLOS ONE 8:e78622. doi: 10.1371/journal.pone.0078622

Fan, D., He, X., Bian, Y., Guo, Q., Zheng, K., Zhao, Y., et al. (2016). Triptolide modulates TREM-1 signal pathway to inhibit the inflammatory response in rheumatoid arthritis. Int. J. Mol. Sci. 17:498. doi: 10.3390/ijms170 40498

Fu, J. J., McDonald, V. M., Baines, K. J., and Gibson, P. G. (2015). Airway IL-1beta and systemic inflammation as predictors of future exacerbation risk in asthma and COPD. Chest 148, 618-629. doi: 10.1378/chest.14-2337

Giuffrida, M. J., and Valero, N. (2017). Increased systemic cytokine/chemokine expression in asthmatic and non-asthmatic patients with bacterial, viral or mixed lung infection. Scand. J. Immunol. 85, 280-290. doi: 10.1111/sji. 12532

Goh, K. I., Cusick, M. E., Valle, D., Childs, B., Vidal, M., and Barabasi, A. L. (2007). The human disease network. Proc. Natl. Acad. Sci. U.S.A. 104, 8685-8690. doi: $10.1073 /$ pnas.0701361104

Haneklaus, M., and O'Neill, L. A. (2015). NLRP3 at the interface of metabolism and inflammation. Immunol. Rev. 265, 53-62. doi: 10.1111/imr. 12285

Hosseinian, N., Cho, Y., Lockey, R. F., and Kolliputi, N. (2015). The role of the NLRP3 inflammasome in pulmonary diseases. Ther. Adv. Respir. Dis. 9, 188-197. doi: 10.1177/1753465815586335

Im, H., and Ammit, A. J. (2014). The NLRP3 inflammasome: role in airway inflammation. Clin. Exp. Allergy 44, 160-172. doi: 10.1111/cea.12206

Jia, A., Wang, Y., Sun, W., Xiao, B., Mu, L., Wei, Y., et al. (2017). Comparison of the roles of house dust mite allergens, ovalbumin and lipopolysaccharides in the sensitization of mice to establish a model of severe neutrophilic asthma. Exp. Ther. Med. 14, 2126-2134. doi: 10.3892/etm.2017. 4776

Kim, R. Y., Pinkerton, J. W., Essilfie, A. T., Robertson, A. A. B., Baines, K. J., Brown, A. C., et al. (2017). Role for NLRP3 inflammasome-mediated, IL-1betadependent responses in severe, steroid-resistant asthma. Am. J. Respir. Crit. Care Med. 196, 283-297. doi: 10.1164/rccm.201609-1830OC

Kim, R. Y., Pinkerton, J. W., Gibson, P. G., Cooper, M. A., Horvat, J. C., and Hansbro, P. M. (2015). Inflammasomes in COPD and neutrophilic asthma. Thorax 70, 1199-1201. doi: 10.1136/thoraxjnl-2014-206736

Kufer, T. A., and Sansonetti, P. J. (2011). NLR functions beyond pathogen recognition. Nat. Immunol. 12, 121-128. doi: 10.1038/ni.1985
Latz, E., Xiao, T. S., and Stutz, A. (2013). Activation and regulation of the inflammasomes. Nat. Rev. Immunol. 13, 397-411. doi: 10.1038/nri3452

Li, D., Chen, D., Zhang, X., Wang, H., Song, Z., Xu, W., et al. (2015). c-Jun $\mathrm{N}$-terminal kinase and Akt signalling pathways regulating tumour necrosis factor-alpha-induced interleukin-32 expression in human lung fibroblasts: implications in airway inflammation. Immunology 144, 282-290. doi: 10.1111/ imm.12374

Li, T., Wang, Y., Wang, Y., Liang, R., Zhang, D., Zhang, H., et al. (2013). Development of an SPE-HPLC-MS method for simultaneous determination and pharmacokinetic study of bioactive constituents of Yu Ping Feng San in rat plasma after oral administration. J. Ethnopharmacol. 145, 784-792. doi: 10.1016/j.jep.2012.12.010

Li, X., Wu, L., Liu, W., Jin, Y., Chen, Q., Wang, L., et al. (2014). A network pharmacology study of Chinese medicine QiShenYiQi to reveal its underlying multi-compound, multi-target, multi-pathway mode of action. PLOS ONE 9:e95004. doi: 10.1371/journal.pone.0095004

Li, Z., Zheng, J., Zhang, N., and Li, C. (2016). Berberine improves airway inflammation and inhibits NF-kappaB signaling pathway in an ovalbumininduced rat model of asthma. J. Asthma 53, 999-1005. doi: 10.1080/02770903. 2016.1180530

Martinon, F., Mayor, A., and Tschopp, J. (2009). The inflammasomes: guardians of the body. Annu. Rev. Immunol. 27, 229-265. doi: 10.1146/annurev.immunol. 021908.132715

Menu, P., and Vince, J. E. (2011). The NLRP3 inflammasome in health and disease: the good, the bad and the ugly. Clin. Exp. Immunol. 166, 1-15. doi: 10.1111/j. 1365-2249.2011.04440.x

Mi Chun, J., Lee, A. R., Seon Kim, H., Lee, A. Y., Jeong Gu, G., Cheol Moon, B., et al. (2017). Peucedanum japonicum extract attenuates allergic airway inflammation by inhibiting Th2 cell activation and production of proinflammatory mediators. J. Ethnopharmacol. 211, 78-88. doi: 10.1016/j.jep. 2017.09.006

Mims, J. W. (2015). Asthma: definitions and pathophysiology. Int. Forum Allergy Rhinol. 5(Suppl. 1), S2-S6. doi: 10.1002/alr.21609

Negash, A. A., Ramos, H. J., Crochet, N., Lau, D. T., Doehle, B., Papic, N., et al. (2013). IL-1beta production through the NLRP3 inflammasome by hepatic macrophages links hepatitis $\mathrm{C}$ virus infection with liver inflammation and disease. PLOS Pathog. 9:e1003330. doi: 10.1371/journal.ppat.100 3330

Niu, X., Lu, C., Xiao, C., Ge, N., Jiang, M., Li, L., et al. (2015). The crosstalk of pathways involved in immune response maybe the shared molecular basis of rheumatoid arthritis and type 2 diabetes. PLOS ONE 10:e0134990. doi: 10.1371/ journal.pone.0134990

Ober, C., and Yao, T. C. (2011). The genetics of asthma and allergic disease: a 21st century perspective. Immunol. Rev. 242, 10-30. doi: 10.1111/j.1600-065X.2011. 01029.x

Peng, S., Gao, J., Liu, W., Jiang, C., Yang, X., Sun, Y., et al. (2016). Andrographolide ameliorates OVA-induced lung injury in mice by suppressing ROS-mediated NF-kappaB signaling and NLRP3 inflammasome activation. Oncotarget 7, 80262-80274. doi: 10.18632/oncotarget.12918

Rossios, C., Pavlidis, S., Hoda, U., Kuo, C. H., Wiegman, C., Russell, K., et al. (2017). Sputum transcriptomics reveal upregulation of IL-1 receptor family members in patients with severe asthma. J. Allergy Clin. Immunol. doi: 10.1016/j.jaci.2017. 02.045 [Epub ahead of print].

Schuliga, M. (2015). NF-kappaB signaling in chronic inflammatory airway disease. Biomolecules 5, 1266-1283. doi: 10.3390/biom5031266

Simpson, J. L., Phipps, S., Baines, K. J., Oreo, K. M., Gunawardhana, L., and Gibson, P. G. (2014). Elevated expression of the NLRP3 inflammasome in neutrophilic asthma. Eur. Respir. J. 43, 1067-1076. doi: 10.1183/09031936.0010 5013

Song, J., Li, J., Zheng, S. R., Jin, Y., and Huang, Y. (2013). Anti-inflammatory and immunoregulatory effects of Yupingfeng powder on chronic bronchitis rats. Chin. J. Integr. Med. 19, 353-359. doi: 10.1007/s11655-0131442-6

Song, T., Hou, X., Yu, X., Wang, Z., Wang, R., Li, Y., et al. (2016). Adjuvant treatment with Yupingfeng formula for recurrent respiratory tract infections in children: a meta-analysis of randomized controlled trials. Phytother. Res. 30, 1095-1103. doi: 10.1002/ptr.5628 
Sun, H., Ni, X., Zeng, D., Zou, F., Yang, M., Peng, Z., et al. (2017). Bidirectional immunomodulating activity of fermented polysaccharides from Yupingfeng. Res. Vet. Sci. 110, 22-28. doi: 10.1016/j.rvsc.2016. 10.015

Tan, Y. F., Zhang, W., Yang, L., and Jiang, S. P. (2011). The effect of formoterol on airway goblet cell hyperplasia and protein Muc5ac expression in asthmatic mice. Eur. Rev. Med. Pharmacol. Sci. 15, 743-750.

Underwood, S., Foster, M., Raeburn, D., Bottoms, S., and Karlsson, J. A. (1995). Time-course of antigen-induced airway inflammation in the guinea-pig and its relationship to airway hyperresponsiveness. Eur. Respir. J. 8, 2104-2113.

Wang, H. Z., Hong, M., Gui, L. L., Hua, Y. Q., and Xu, H. Q. (2013). Effect of Yupingfeng San against OVA-induced allergic asthma in mice. Zhongguo Zhong Yao Za Zhi 38, 1052-1055.

Zhao, N., Li, J., Li, L., Niu, X. Y., Jiang, M., He, X. J., et al. (2015). Molecular network-based analysis of Guizhi-Shaoyao-Zhimu decoction, a TCM herbal formula, for treatment of diabetic peripheral neuropathy. Acta Pharmacol. Sin. 36, 716-723. doi: 10.1038/aps.2015.15
Zhong, Y., Wang, X., Xu, G., Mao, B., Zhou, W., Min, J., et al. (2014). Modified Yupingfeng formula for the treatment of stable chronic obstructive pulmonary disease: a systematic review of randomized controlled trials. Afr. J. Tradit. Complement. Altern. Med. 11, 1-14.

Conflict of Interest Statement: The authors declare that the research was conducted in the absence of any commercial or financial relationships that could be construed as a potential conflict of interest.

The reviewer YZ and handling editor declared their shared affiliation.

Copyright (c) 2017 Liu, Shen, Fan, Qiu, Guo, Zheng, Luo, Shu, Lu, Zhang, Lu, Ma and He. This is an open-access article distributed under the terms of the Creative Commons Attribution License (CC BY). The use, distribution or reproduction in other forums is permitted, provided the original author(s) or licensor are credited and that the original publication in this journal is cited, in accordance with accepted academic practice. No use, distribution or reproduction is permitted which does not comply with these terms. 